\title{
Spirituality in Knowledge Management: Systematic Literature Review and Future Studies Suggestions
}

\author{
Raysa Rocha ${ }^{1}$, Paulo Pinheiro ${ }^{2}$ \\ ${ }^{1}$ Universidade da Beira Interior, Covilhã, Portugal \\ ${ }^{2}$ NECE Research Unit in Business Sciences, University of Beira Interior, Covilhã, Portugal \\ raysa.geaquinto@gmail.com \\ pgp@ubi.pt
}

\begin{abstract}
Knowledge Management has established itself as key to the competitive advantage of companies in the $21^{\text {st }}$ century. As the mere accumulation of knowledge is insufficient, there is a corresponding need to control and supervise interactions across the organization to create organisational value. Thus, understanding how the composition of the main knowledge management constructs and what influences them is especially important. This research seeks to understand how spirituality amounts to a factor influencing the Knowledge Management. We opted to undertake a systematic review of the literature in order to understand just which links among the constructs feature in the literature. Therefore, we made searches on Web of Science and EBSCO databases. The main contribution of this article is literature systematization and categorization. Our results suggest that spirituality positively influences organizational learning, organizational wisdom, knowledge creation and knowledge sharing. However, we would emphasise that there are almost no articles interlinking these two constructs and hence the need to deepen research into this factor and improve our understanding of its influence in organisations and therefore also present suggestions to future research and the application of different methodologies to advance studies on this subject.
\end{abstract}

Keywords: Knowledge, Knowledge Management, Spirituality, Workplace Spirituality, Systematic Literature Review

\section{INTRODUCTION}

Organisations need to ensure control over the knowledge they create, store, share, apply and/or lose so as to transform it into assets, maintain their competitive advantages and create value to achieve their own long term survival (Nonaka, 1994; Argote and Ingram, 2000; Wang and Noe, 2010). We follow the Knowledge Management model presented by Jordan and Jones (1997) in which there are five categories, acquisition of knowledge; problem solving; dissemination, property and memory. Knowledge Sharing is a fundamental factor for the creation of organisational value (Argote and Ingram, 2000). Therefore, there is a need to foster a favourable organisational environment coupled with continued dialogue among members (Nonaka, Lewin and Nonaka, 1994).

Spirituality influences the creation of such environments as this fosters the moral and emotional evolution of organisational members as well as their sense of integrity, truth and understanding (Rowley, 2006) while also generating mutual trust (Mitroff and Denton, 1999; Walker, 2013), and feelings of belonging to a greater whole (Delbecq, 1999). Due to these characteristics, we may consider spirituality holds a positive influence over Knowledge Management (Robledo, 2014; Tecchio, Cunha and Brand, 2018). Nevertheless, very few scientific studies have focused on this area (Tejeda, 2015; Walt and Swanepoel, 2015; Tecchio, Cunha and Brand, 2018).

The relevance of this research stems from deepening the study of the role of spirituality in fostering Knowledge Management (Asrar-ul-Haq and Anwar, 2016; Tejeda, 2015; Walt and Swanepoel, 2015). Therefore, the objective of this article is literature systematization and categorization to investigate how spirituality constitutes a factor of influence in Knowledge Management. To achieve this objective, we carried out a systematic review of the literature in the expectation of contributing both theoretical and practical terms as regards how organisations might reconsider their spiritual interactions and the management of their knowledge within the scope of boosting their competitive advantages.

The article first sets out the antecedents to Knowledge Management and spirituality. We then move on to detail the methodology applied, the systematic literature review before discussing the results returned. We close by presenting our final considerations, the research limitations and our suggestions for future studies. 


\section{ANTECEDENTS}

\subsection{Knowledge Management}

The literature suggests that knowledge is originally in the individual, becoming organisational when these individual skills are used in favor of the organization (Nonaka, 1994; Erden et al, 2008). Recognizing the individual as a limited receptacle of knowledge, the organization must have experts and coordinate these skills to achieve their goals. Therefore, the organization can be seen as an institution to integrate knowledge (Grant, 1996).

Polanyi (1967) divides knowledge into tacit and explicit. The first is the knowledge inherent in the individual is related to intuition, the know-how, you cannot express it formally. The second, in turn, is that which can be expressed in words, is codifiable. We can affirm that when there is knowledge sharing there is also creation, since the interaction can also generate knowledge for the speaker (Wilkesmann and Wilkesmann, 2011).

To explain how the creation and KS takes place in organisations, we applied the spiral of knowledge and its conversion models: (i) socialisation; (ii) externalisation; (iii) combination; and (iv) internalisation. The spiral arises from the dynamics ongoing between tactic and explicit knowledge. One of the requirements to the occurrence of such processes is mutual trust, which acts to accelerate and facilitate KS process (Davenport and Prusak, 1998; Nonaka, 1994).

The sharing of organisational knowledge represents a continuous process (Nonaka, Lewin and Nonaka, 1994; Grant, 1996), needing the transmission and reception of knowledge within the framework of factors of information such as the nature of the knowledge, the surrounding organisational culture, motivation and the opportunity for sharing (Ipe, 2003). The reception of knowledge depends on the capacity for absorption and the aggregation of knowledge that directly interlinks with the species of knowledge undergoing sharing (Grant, 1996; Ipe, 2003). Both phases of KS hold relevance as they may impact on the quality of the sharing process (Tang, 2011). There is the need for the receptor to hold the competences and abilities to aggregate the knowledge as otherwise shortcomings and gaps might then emerge in the transmission process (Tang, 2011). The quality of sharing may be measured by the creation of new knowledge and the alterations subsequently enacted to performances (Argote and Ingram, 2000).

All of these interactions take place in an environment containing the physical, mental and/or virtual components entitled ba (Nonaka and Konno, 1998). Socialisation, an interaction key to the creation of knowledge, returns greater levels of efficiency when occurring in physical spaces, in face-to-face interactions in which there is mutual trust, love, care and commitment (Nonaka and Konno, 1998).

In addition to environments favourable to the creation and KS, interactions among organisational members need fostering to lead to their integration into a single body and mind without any need for explicit rules and processes. Thus, members should adopt shared purposes, feelings and thinking as if a single entity through to reaching the level of collective improvisation in which the group creates a collective mind and body (Erden, von Krogh and Nonaka, 2008).

This should deploy the knowledge and, especially, just when and how to apply it and, therefore, the existence of knowledge is not in itself enough to ensure the management of the decisions appropriate to returning the competitive advantages expected. Nonaka and Takeuchi (2011) use the original concept of phronesis brought by Aristotle to explain practical wisdom as the empirical knowledge that enables ethically sound decisions. The development of wisdom depends on three factors, experience, spirituality and passion for learning (Hays, 2007; Bierly III et al., 2000). Furthermore, such decisions do not depend only on rationality but instead also incorporate psychological and spiritual aspects that need taking into consideration (Izak, 2013). Spirituality associates with the moral and emotional evolution of the organisation's members, in particular as regards self-reflection, contemplating their failures and successes, establishing differentiated targets, a sense of integrity and truth and an understanding of position (Rowley, 2006).

Despite its sheer relevance, the influence of spirituality on Knowledge Management has only come in for study in a modest fashion (Gallagher, Rocco and Landorf, 2007; Sorakraikitikul and Siengthai, 2014; Rahman et al., 2015; Walt and Swanepoel, 2015; Tecchio, Cunha and Brand, 2018). Hence, there is every justification for a deeper consideration of the role, functions and consequences of spirituality in organisations (Robledo, 2014). 


\subsection{Spirituality}

Even while a relatively unexplored theme in Management Science, spirituality has been subject to relevant organisational studies (Poole, 2009; Pawar, 2017). We would highlight how spirituality does not represent any closed concept but is rather fluid and interdisciplinary and hence the lack of any conceptual clarity (Poole, 2009; Pawar, 2017). Therefore, studies apply the respective components of spirituality to approach the concept. It is here also necessary to clarify the difference between spirituality and religion. While there may be the former in religions, there is no religion in spirituality as there are neither dogmas nor rites in spirituality (Brophy, 2015).

In this study, we adopt spirituality as a mutual sense among individuals (Mitroff and Denton, 1999; Walker, 2013), such as the feeling of belonging to a greater whole (Delbecq, 1999). Applied to the organisational scenario, spirituality in organisations spans the nurturing and fostering of experiences of mutuality, trust, the feeling of belonging, interconnections, meaning, purpose, the improvement and transcendence of members (Duchon \& Plowman, 2005) leading to a rise in satisfaction with the working environment as well as its prevailing levels of creativity, motivation, commitment and competence (Rego and Cunha, 2008).

Furthermore, the positive consequences only emerge when the practice of spirituality becomes a habit, occurring subconsciously or, in other words, becoming inherent to the practitioners (Cavanagh and Bandsuch, 2002; Gallagher, Rocco and Landorf, 2007). These subconscious habits within organisations may facilitate improvements in organisational environments and there is the scope for positively influencing the mutual trust necessary to $\mathrm{KS}$.

\section{METHODOLOGY AND RESULTS ANALYSIS}

We undertook a systematic review of the literature (Wright, Brand, Dunn and Spindler, 2007) through means of a replicable and pre-established protocol applied to the collection and analysis of the most relevant articles (Denyer and Tranfield, 2009). The principles of accessibility, focus, equality in the treatment of articles and transparency underpin this research study (Thorpe, Holt and MacPherson, 2005).

With the goal of ensuring the relevance and pertinence of the articles identified, we set down criteria for their inclusion and exclusion prior to beginning the search: a) Including only articles within the field of study (Knowledge Management); b) Excluding articles that approach spirituality in religion; c) Including only those deploying a scientific methodology of analysis; d) Including only those articles published in either English and/or Portuguese; e) Including only those scientific articles published in scientific journals (Podsakoff et al., 2005).

The search terms applied were the following: 1st - "Knowledge" and "Spirituality"; 2nd - "Knowledge Management" and "spiritual*", with the following criteria: "Academic Search Complete" and "Business Source Complete", "boolean/phrase"; "also search within the full text of the articles"; for the period between 1990 and 2018, "full text" and "Academic Journal". Studies involving religions (for example: Aslan Guemuesay, 2012), without any scientific methodology (for example: Arora, 2009), falling beyond the Management field (for example: Valackiene and Demeniene, 2007) were withdrawn from analysis. The first search of the Web of Knowledge database returned 937 articles. Following this analytical procedure, applying the pre-determined quality standard resulted in only nine theoretical and empirical articles. A second search resulted in four articles after applying both the respective criteria and excluding duplicates. In the EBSCO database, the first result generated 116 articles. We then analysed the titles and abstracts to ascertain the stipulated quality. The final total resulting from this search was just four scientific theoretical and empirical articles (Wright, Brand, Dunn and Spindler, 2007). In a second search, following the exclusion of three duplicate articles, one conference article and one article beyond this field of study, we selected the remaining four articles.

In keeping with the phases followed in this Systematic Literature Review, the figure below sets out the five phases: 


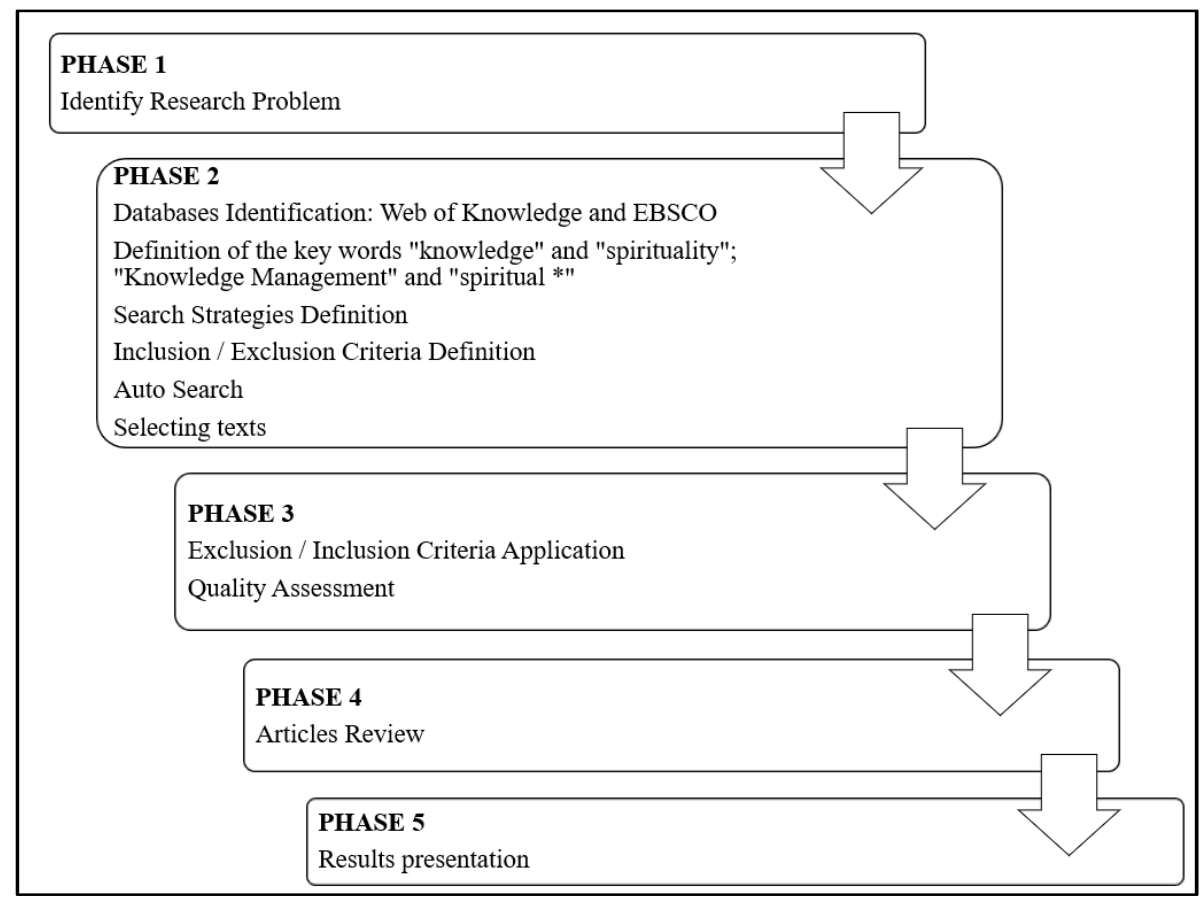

Figure 1. Phases in the Systematic Literature Review.

Source: Adapted from Tranfield, Denyer and Smart (2003); Denyer and Tranfield (2009) and Rouseau, Manning and Denyer (2008).

We would note how over the last two decades there were only 21 publications and only in the last six years did the quantity of publications begin rising. This only serves to reinforce the gaps existing and the need to deepen research on this theme. The graph below depicts the annual trend in the scientific articles selected following the searches and the respective exclusions.

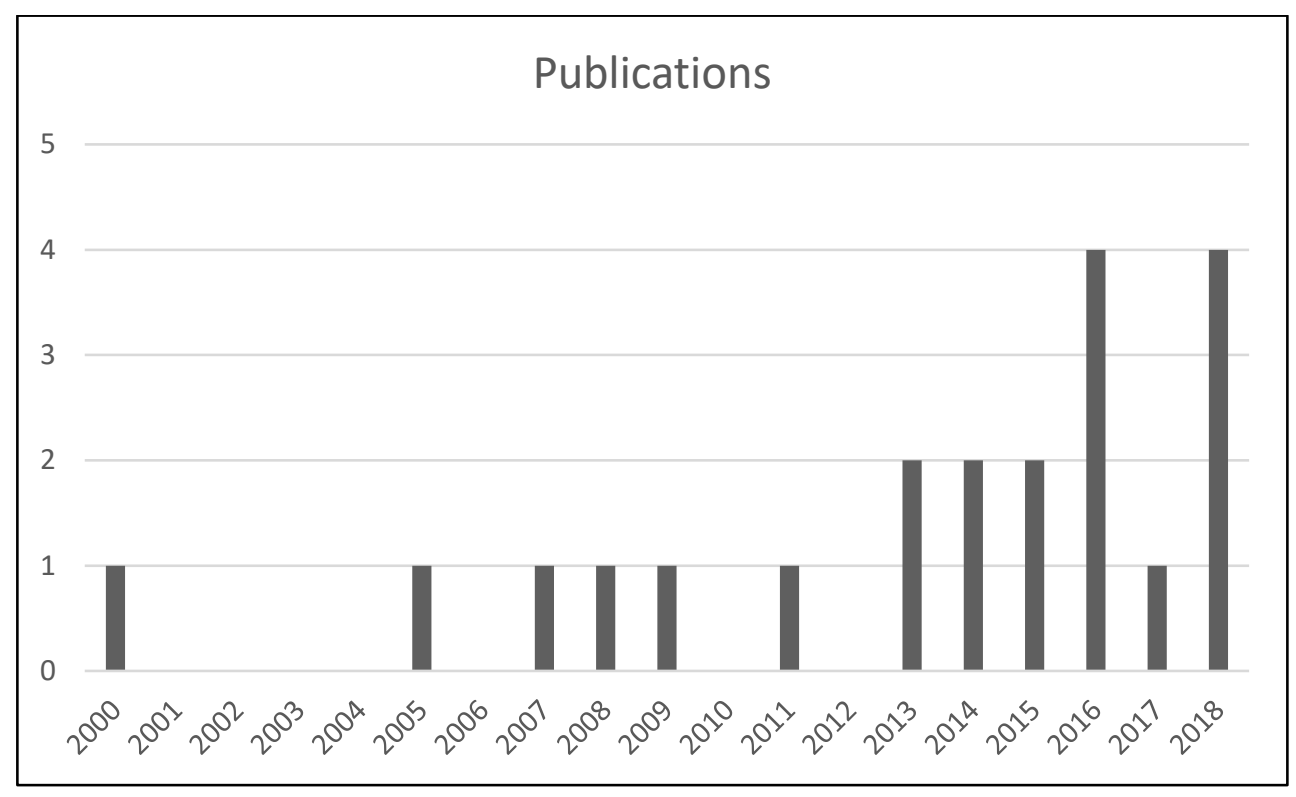

Figure 2. Publications per year.

Source. Authors' own. 


\section{DISCUSSION}

Knowledge Management requires exploration within the scope of conciliating its interactions among the existing organisational structures so as to ensure knowledge makes a difference in some material, aesthetic or spiritual fashion (Alrawi, 2008). Spiritual environments are also favourable to the creation of knowledge (Tecchio, Cunha and Brand, 2018). As well as attaining the efficient KS, spirituality should extend into the working environment in terms of trust and minimising the perceived risks among individuals (Rahman et al., 2015). Kari and Sinha (2017) propose that spirituality generates a positive role in the workplace as regards intentions to share, displaying a holistic structure and multiple levels interconnecting spirituality in the workplace and transformational leadership with the intention to share knowledge. There is also a positive relationship between the organisational learning culture and spirituality in the workplace, partially mediated through KS (Sorakraikitikul and Siengthai, 2014).

Rahman et al. (2015) study the antecedents to KS and encounter a strong relationship between spirituality in the workplace and KS with the variables for risk perceived as partially mediating the association between trust and KS. Furthermore, Rahman et al. (2018), who also approach the antecedents to the effective KS, maintain that each of the five major personality characteristics impact on tacit KS behaviours within the framework of higher education teaching staff except for the personality trait for conscientiousness. Indeed, motivation, selfefficiency and mutual trust also play significant roles in the tacit behaviours surrounding KS.

Bratianu (2018) proposes the extension of the tacit and explicit knowledge dimensions into the rational, emotional and spiritual areas especially through exploring the risks of loss, emptiness, overspills and inappropriate usage of knowledge (Bratianu, 2018). Spirituality also appears in Knowledge Management studies as a species of knowledge for the workplace learning process, as emancipatory knowledge, thus knowledge loaded with emotions, values and visions and thus differentiated from other species of knowledge (Gallagher, Rocco and Landorf, 2007). This perception of spiritual knowledge incorporates tacit knowledge as a source of intellectual capital. Spiritual knowledge thus reflects not only a set of organisational values but also the structure of organisational behaviour (Bejinaru, 2016).

De Angelis (2016) proposes spiritual intelligence as part of the universe of intelligences necessary to the process of learning among individuals whether or not belonging to the same culture and proposes that KS is power and potentially intelligent. Organisational learning has undergone a process of mystification due to the characteristics of the field, the conceptual diversity; the anthropomorphism of phenomena; the division between visionaries and sceptics; the reification of terminology and as well as the mystification of the very concept. Recourse to learning may thus stem from more spiritual than instrumental approaches. Hence, mystification performs an important role in reformulating organisational learning as a spiritual search that embodies the search for knowledge (Friedman, Lipshitz and Popper, 2005).

The limited success of Knowledge Management and the complexity of organisational environments has triggered discussion about Organisational Wisdom. This reflects a polysemic concept containing different meanings in different contexts and applications. There is only agreement that knowledge, experience and action constitute core factors. However, there remains little reference to the spiritual dimension of wisdom (Rowley and Slack, 2009). However, Bierly, Kessler and Christensen (2000) do put forward a learning process that includes data, information, knowledge and wisdom and identifying experience, the passion to learn and spirituality as the foundations of organisational wisdom. Wisdom may provide a basis for discovering, perceiving, understanding and resolving the countless questions that emerge out of the nexus between wisdom and the information technologies. The manner and the depth of responses made to the challenges emerging in the field hold just as much importance as the content of those responses (Dalal and Pauleen, 2019).

Izak (2013) also defends that there lacks the means of stipulating some universal construct for wisdom and that the concept of stupidity interconnects with the lack of wisdom and its opposite. This author furthermore defends how the differences between stupidity and wisdom constitute the interrelationship and any research inevitably ends up facing the Wisdom/Stupidity binary. This sets out stupidity as an important concept both for organisations and societies, interrelated with imbalances and shortcomings, with the cognitive fallacies of stupidity identified as: a) unrealistic optimism; b) egocentrism; c) omniscience; d) omnipotence; e) invulnerability. Therefore, wise organisational attitudes derive from the incorporation of psychological and 
spiritual factors and not only rational facets (Izak, 2013).

Robledo (2014) defends the establishment of some metatheory for management, integrative and holistic theory for the harmonious, progressive and integral social development. In 3D or Three Dimensional Management Theory, there are three basic factors operating in harmony: science, the arts and ethics. The need for the involvement and integration of these dimensions renders spirituality as the fourth dimension that brings unity and meaning. Spirituality leads directly to wisdom in generating greater integration between thought and actions, between the organisation and its members, between the surrounding environment and the universe. Therefore, the spiritual dimension of the organisation provides an essential ingredient to management as this unifies its dimensions and ensures its members feel as if part of the mind, body and soul of the organisation and therefore acting in mutual harmony (Robledo, 2014).

Noordin and Karim (2015) maintain that boosting innovation performance levels requires members improve their emotional and spiritual quotients while the organisation works to improve its own Knowledge Management practices. Therefore, organisations need to manage and evaluate their Knowledge Management (Shahgholian and Hajihosseini, 2011). Corner and Pavlovich (2016) approach the relationship between Knowledge Management and spirituality in terms of how the creation of internal knowledge serves as a means for fostering shared value, thus, social benefits and profits. Meanwhile, Walker (2013) directs research towards the relationships ongoing between spirituality and an intelligent and sustainable economy.

The table below summarises and groups the approaches deployed by each of the articles returned by the search and the selection stages detailed above.

Table 1. Approach on Knowledge Management (KM) and Spirituality.

\begin{tabular}{|l|l|}
\hline \multicolumn{1}{|c|}{ Approach on KM and Spirituality } & \multicolumn{1}{c|}{ Authors and Year of Publication } \\
\hline Organizational learning & $\begin{array}{l}\text { Bierly, Kessler and Christensen (2000); Friedman, } \\
\text { Lipshitz and Popper (2005) }\end{array}$ \\
\hline Social Benefits & $\begin{array}{l}\text { Corner and Pavlovich (2016); Walker, (2013); Alrawi } \\
\text { (2008); Gallagher, Rocco and Landorf (2007) }\end{array}$ \\
\hline Wisdom & $\begin{array}{l}\text { Dalal and Pauleen (2019); Izak, (2013); Rowley and } \\
\text { Slack (2009) }\end{array}$ \\
\hline Intention to Share & Kari and Sinha (2017); Rahman et al. (2016) \\
\hline Background to Knowledge Sharing & $\begin{array}{l}\text { Rahman et al. (2018); Rahman et al., (2015); } \\
\text { Sorakraikitikul and Siengthai (2014); }\end{array}$ \\
\hline Creation of 3D Management Theory & Robledo (2014) \\
\hline Knowledge Creation and Spirituality & Tecchio, Cunha and Brand (2018) \\
\hline Knowledge / Spiritual Intelligence & $\begin{array}{l}\text { Bratianu (2018); Bejinaru (2016); De Angelis (2016) } \\
\text { Noordin and Karim (2015) }\end{array}$ \\
\hline Knowledge Management Evaluation & Shahgholian and Hajihosseini (2011) \\
\hline
\end{tabular}

Source: Authors' own.

These studies confirm the relevance and influence of spirituality into several of the components of Knowledge Management. Nevertheless, we would also certainly point to the need for deeper and wider studies on the theme and correspondingly set out our proposals for future studies below. 


\section{FINAL CONSIDERATIONS}

Spirituality has been neglected for years by the Management Science research community with shortcomings in the literature requiring studying and filling as is the case with Knowledge Management, a relatively new theme in the literature. We consider that there are two fields particularly subject to improvement, including the need for relevant advances in their respective interrelationship.

This work reveals that spirituality bears a positive influence on the trust necessary to ensuring KS as organisations that foster a spiritual environment demonstrate greater trust among their members and thereby facilitating the sharing of organisational knowledge (Gallagher, Rocco and Landorf, 2007; Robledo, 2014; Rahman et al., 2015; Tecchio, Cunha and Brand, 2018).

Spirituality has an important role to play in organisational theory and practice. However, this also places a heavy burden on practice. The main limitation stems from the method both in terms of the quantity of the articles encountered and the quantity of databases made recourse to (two) and the searches made of each database (two). We would also point to the lack of empirical testing as limiting this study. We would therefore suggest that studies be made with differing methodologies (quantitative and qualitative); as well as other systematic reviews of the literature incorporating other terms and databases.

Finally, as spirituality in Knowledge Management represents a recent theme and in need of research (Tecchio, Cunha and Brand, 2018; Pawar, 2017), we would set out the following proposals for future studies:

(i) Efficient and effective methods for managing organisational spirituality; (ii) Identifying the main positive/negative interferences in spiritual knowledge sharing; and (iii) Efficient and effective means of spiritual knowledge sharing inside organisations as studying spirituality as a theory is not enough and there is a corresponding need for organisations to be able to apply and manage spirituality for the creation of value.

(iv) Establishing criteria and scales to measure the characteristics of organisational spirituality; as from the moment when spirituality becomes part of organisations, there arises the need to measure the level of prevailing organisational spirituality so that leaders have the information available for appropriate decision making able to nurture organisational spirituality.

(v) Empirical studies on the specific benefits of spiritual knowledge to organisations. Given that Gallagher, Rocco and Landorf (2007) present spiritual knowledge as emancipatory knowledge, there is a need for deeper study on this subject. Hence, organisations would also gain access to studies to aid in managing and creating value through such knowledge.

(vi) The role of leaders in organisational spiritual Knowledge Management as studies demonstrate that leadership represents the main actors in fostering spirituality (Pawar, 2014) even while there remain few studies, especially theoretical works, on the issue.

(vii) The relationship between spirituality and organisational wisdom; this suggestion arises from the studies of Bierly, Kessler and Christensen (2000) that nominate spirituality as one of the pillars for the development of wisdom. Therefore, learning more about the role of spirituality holds relevance.

(viii) The influence of spirituality over the creation of ba. Tecchio, Cunha and Brand (2018) highlight how ba (Nonaka and Konno, 1998) conveys characteristics present in environments in which spirituality also has a presence and therefore research needs to consider whether the influence of $b a$ is of relevance to this theme.

\section{References}

Alrawi, K. W. (2008) 'Knowledge management and organization's perception in the United Arab Emirates: Case study', International Journal of Commerce and Management, 18(4), pp. 382-394. doi: 10.1108/10569210810921988.

De Angelis, C. T. (2016) 'The impact of national culture and knowledge management on governmental 
intelligence', Journal of Modelling in Management, 11(1), pp. 240-268.

Argote, L. and Ingram, P. (2000) 'Knowledge transfer: A basis for competitive advantage in firms', Organizational Behavior and Human Decision Processes, 82(1), pp. 150-169. doi: 10.1006/obhd.2000.2893.

Arora, V. K. (2009) 'Engineering the soul of management in the nano era', Chinese Management Studies, 3(3), pp. 213-234. doi: 10.1108/17506140910984078.

Aslan Guemuesay, A. (2012) 'Boundaries and knowledge in a Sufi Dhikr Circle', Journal of Management Development, 31(10), pp. 1077-1089. doi: 10.1108/02621711211281861.

Asrar-ul-Haq, M. and Anwar, S. (2016) 'A systematic review of knowledge management and knowledge sharing: Trends, issues, and challenges', Cogent Business and Management. Cogent, 3(1), pp. 1-17. doi: 10.1080/23311975.2015.1127744.

Bejinaru, R. (2016) 'Knowledge Dynamics Impact on Intellectual Capital in Organizations', Management Dynamics in the Knowledge Economy, 4(4), pp. 515-534. Available at: https://search.proquest.com/docview/1861825442? accountid=17242.

Bierly, P. E., Kessler, E. H. and Christensen, E. W. (2000) 'Organizational learning, knowledge and wisdom', Journal of Organizational Change Management, 13(6), pp. 595-618. doi: 10.1108/09534810010378605.

Bratianu, C. (2018) 'A Holistic Approach to Knowledge Risk', Management Dynamics in the Knowledge Economy, 6(4), pp. 593-607. doi: 10.25019/mdke/6.4.06.

Brophy, M. (2015) 'Spirituality Incorporated: Including Convergent Spiritual Values in Business', Journal of Business Ethics, 132(4), pp. 779-794. doi: 10.1007/s10551-014-2337-y.

Cavanagh, G. F. and Bandsuch, M. R. (2002) 'Virtue as a Benchmark for Spirituality in Business', Journal of Business Ethics, 38, pp. 109-117.

Dalal, N. and Pauleen, D. J. (2019) 'The wisdom nexus: Guiding information systems research, practice, and education', Information Systems Journal, 29(1), pp. 224-244. doi: 10.1111/isj.12196.

Delbecq, A. L. (1999) 'Christian spirituality and contemporary business leadership', Journal of Organizational Change Management, 12(4), pp. 345-354. doi: 10.1108/09534819910282180.

Denyer, D. and Tranfield, D. (2009) 'Producing a systematic review', in Stage Handbook of Organizational Research.

Erden, Z. et al. (2008) 'The quality of group tacit knowledge', Journal of Strategic Information Systems, 17(1), pp. 4-18. doi: 10.1016/j.jsis.2008.02.002.

Friedman, V. J., Lipshitz, R. and Popper, M. (2005) 'The mystification of organizational learning', Journal of Management Inquiry, 14(1), pp. 19-30. doi: 10.1177/1056492604273758.

Gallagher, S. J., Rocco, T. S. and Landorf, H. (2007) 'A Phenomenological Study of Spirituality and Learning Processes at Work: Exploring the Holistic Theory of Knowledge and Learning', Human Resource Development Quarterly, 18(4), pp. 457-480. doi: 10.1002/hrdq.

Grant, R. (1996) 'Toward a knowledge based theory of the firm.', Strategic Management Journal, 17(17), pp. 109-122. doi: 10.2307/2486994.

Ipe, M. (2003) 'Knowledge Sharing in Organizations: A Conceptual Framework', Human Resource Development Review, 2(4), pp. 337-359. doi: 10.1177/1534484303257985.

Izak, M. (2013) 'The foolishness of wisdom: Towards an inclusive approach to wisdom in organization', Scandinavian Journal of Management. Elsevier Ltd, 29(1), pp. 108-115. doi: 10.1016/j.scaman.2012.07.002.

Jordan, J. and Jones, P. (1997) 'Assessing your company's Knowledge Management style', Long Range Planning, 30(3), pp. 392-398.

Mitroff, I. I. and Denton, E. A. (1999) 'A Study of Spirituality in the Workplace', Sloan Management Review, pp. 83-92.

Nonaka, I. and Konno, N. (1998) 'The Concept of "Ba”: Building a Foundation for Knowledge Creation', California Management Review, 40(3), pp. 40-54. doi: 10.2307/41165942.

Nonaka, I., Lewin, A. Y. and Nonaka, I. (1994) 'A Dynamic Theory of Organizational Knowledge Creation', Organization Science, 5(1), pp. 14-37. doi: 10.1287/orsc.5.1.14.

Noordin, M. F. and Karim, Z. A. (2015) 'Modeling the Relationship between Human Intelligence, Knowledge Management Practices, and Innovation Performance', Journal of Information \& Knowledge Management, 14(01), pp. 1550012-1. doi: 10.1142/s0219649215500124.

Pawar, B. S. (2014) 'Leadership Spiritual Behaviors Toward Subordinates: An Empirical Examination of the Effects of a Leader's Individual Spirituality and Organizational Spirituality', Journal of Business Ethics, 122(3), pp. 439452. doi: 10.1007/s10551-013-1772-5.

Pawar, B. S. and Authors, F. (2017) 'The relationship of individual spirituality and organizational spirituality with meaning and community at work An empirical examination of the direct effects', Leadership \& Organization Development Journal. doi: 10.1108/LODJ-01-2016-0014. 
Podsakoff, P. et al. (2005) 'The Influence of management journals in the 1980's and 1990's', Strategic Management Journal, 26, pp. 473-488.

Poole, E. (2009) 'Organisational Spirituality - A Literature Review', Journal of Business Ethics, 84, pp. 577-588. doi: 10.1007/s10551-008-9726-z.

Rahman, M. S. et al. (2015) 'Trust and work place spirituality on knowledge sharing behaviour: Perspective from non-academic staff of higher learning institutions', Learning Organization, 22(6), pp. 317-332. doi: 10.1108/TLO05-2015-0032.

Rego, A. and Cunha, M. P. e (2008) 'Workplace spirituality and organizational commitment: An empirical study', Journal of Organizational Change Management, 21(1), pp. 53-75.

Robledo, M. A. (2014) 'Building an integral metatheory of management', European Management Journal. Elsevier Ltd, 32(4), pp. 535-546. doi: 10.1016/j.emj.2013.10.008.

Rowley, J. (2006) 'What do we need to know about wisdom?', Management Decision, 44(9), pp. 1246-1257. doi: 10.1108/00251740610707712.

Rowley, J. and Slack, F. (2009) 'Conceptions of wisdom', Journal of Information Science, 35(1), pp. 110-119. doi: $10.1177 / 0165551508092269$.

Shahgholian, K. and Hajihosseini, H. (2011) 'Designing a model for evaluation of knowledge management level in industrial organizations of Iran (Auto industry)', African Journal of Business Management, 5(2), pp. 332-339.

Sorakraikitikul, M. and Siengthai, S. (2014) 'Organizational learning culture and workplace spirituality', The Learning Organization, 21(3), pp. 175-192. doi: 10.1108/tlo-08-2011-0046.

Tang, F. (2011) 'Knowledge Transfer in Intra-Organization Networks', Systems Research and Behavioral Science, 282, pp. 270-282. doi: 10.1002/sres.

Tecchio, E. et al. (2018) 'Espiritualidade nas organizações e criação de conhecimento Spirituality in organization and knowledge creation', Organizações em Contexto, São Bernardo do Campo, 14(27), pp. 397-426.

Tejeda, M. J. (2015) 'Exploring the Supportive Effects of Spiritual Well-Being on Job Satisfaction Given Adverse Work Conditions', Journal of Business Ethics, 131(1), pp. 173-181. doi: 10.1007/s10551-014-2269-6.

Thorpe, R., Holt, R. and MacPherson, A. (2005) 'Using Knowledge within small and medium-sized firms: a systematic review of the evidence', Journal of Management Reviews, 7(4), pp. 257-281.

Tranfield, D., Denyer, D. and Smart, P. (2003) 'Towards a methodology for developing evidence-informed management', British Journal of Management, 14, pp. 207-222.

Valackiene, A. and Demeniene, A. (2007) 'Knowledge Management: the Development of Testing Portal for Selection of Profession', Inzinerine Ekonomika-Engineering Economics, 2(2), pp. 59-64.

Walker, S. (2013) 'Design and Spirituality: Material Culture for a Wisdom Economy', Design Issues, 29(3), pp. 89107.

van der Walt, F. and Swanepoel, H. (2015) 'The relationship between workplace spirituality and job involvement: A South African study', African Journal of Business and Economic Research, 10(1), pp. 95-116.

Wang, S. and Noe, R. A. (2010) 'Human Resource Management Review Knowledge sharing : A review and directions for future research', Human Resource Management Review. Elsevier Inc., 20(2), pp. 115-131. doi: 10.1016/j.hrmr.2009.10.001.

Wright, R. W. et al. (2007) 'How to write a systematic review', Clinical Orthopedics and Related Research, 455, pp. 23-29. 